\title{
Informatização do trabalho: A substituição do trabalhador por máquinas e seus impactos na QVT
}

\section{Computarization of the workplace: Worker replacement by machines and its impacts on $Q W L$}

\author{
Ariane Dioane Carvalho Barbosa ${ }^{1}$, Glenda Nunes Duarte2, Diego Saimon de Souza \\ Abrantes $^{3 *}$, Beatriz Maciel Santos ${ }^{4}$
}

${ }^{1}$ Acadêmica de Psicologia no Instituto Macapaense do Melhor Ensino Superior. Macapá-AP, Brasil. E-mail: arianeccarvalho98@gmail.com. ${ }^{2}$ Acadêmica de Psicologia no Instituto Macapaense do Melhor Ensino Superior. Macapá-AP, Brasil. E-mail: glendaduarte16ph@gmail.com ${ }^{3}$ Psicólogo/coach, mestre, professor no Instituto Macapaense do Melhor Ensino Superior. Macapá-AP, Brasil. E-mail: diego_saimon@hotmail.com *autor para correspondência

${ }^{4}$ Acadêmica de Psicologia no Instituto Macapaense do Melhor Ensino Superior. Macapá-AP, Brasil. E-mail: beatrizmacielsantos@gmail.com

\author{
Palavras-chave \\ Qualidade de vida \\ Tecnologia \\ Informatização \\ Trabalho
}

\begin{abstract}
Sabe-se que a modernização é inerente aos modelos de negócios atuais, diminuindo, muitas vezes, a presença humana em algumas atividades e tornando determinadas profissões obsoletas, extintas. Assim, objetivou-se identificar como a substituição dos trabalhadores pelas máquinas interfere na qualidade de vida no trabalho (QVT) de funcionários que permanecem nas empresas, em específico as implicações psicológicas decorrentes disso. A pesquisa foi de natureza qualitativa e bibliográfica, sendo baseada no modelo dialético de a nálise e interpretação dos dados. Seu universo foram os artigos científicos com os indicadores: qualidade de vida no trabalho; tecnologia; substituição do trabalhador; informatização do trabalho. Utilizaram-se referências nacionais e estrangeiras e como resultados, descobriu-se que a substituição do trabalhador pelas máquinas acarreta, nos funcionários, uma pressão emocional para que se adequem ao novo funcionamento empresarial, propiciando interferências negativas na labuta, que geram estresse, tristeza e ansiedade, diminuindo a QVT. Percebeu-se que essa dinâmica aumenta a substituição dos mesmos até por outras pessoas, dado sua queda de produtividade.
\end{abstract}

\section{Keywords}

Quality life

Technology

Computerization

Work
It is known the modernization is inherent to the current business models, commonly reducing the human presence in some activities and becoming obsolete some professions, old. The objective was to identify how the worker replacement for machines interferes in the quality working life (QWL) of employees who remain at the companies, specifically the psychological implications resulting from this. The research had a qualitative and bibliographic nature, had been based on the dialectical model of data analysis and interpretation. Its universe was scientific articles with the indicators: quality workin life; technology; worker replacement; computerization of the workplace. National and foreign references were used and as result, it was discovered that the replacement of workers by the machines causes, in the employees, an emotional pressure to adapt to the new business way of functioning, providing negative interferences in the work, which induce stress, sadness and anxiety, decreasing QWL. All this may generate their displacement even for another person as well.

\section{INTRODUÇÃO}

É certo que a tecnologia está presente no dia-a-dia das pessoas com frequência significativa. Este estudo constituiuse por assuntos que abordavam os impactos que as tecnologias podem causar nos funcionários que permanecem em uma determinada empresa após testemunharem colegas serem demitidos para dar lugar às máquinas. Buscou-se a compreensão de que consequências negativas a substituição do trabalhador pelas máquinas incorre na qualidade de vida dos funcionários de uma empresa. Para alcançar isso, usou-se o método bibliográfico com análise qualitativa e dialética dos dados.

Motivou-se na compreensão do conceito de qualidade de vida no trabalho (QVT) e suas variações em diferentes décadas. Isso foi feito através da análise de pesquisas com base em investigações de campo. Com o avançar do estudo, identificou-se que a informatização do trabalho era um tema central para se chegar ao processo de substituição do homem pela máquina. Por isso, posteriormente, estudou-se suas temáticas relacionadas, como os avanços tecnológicos nas empresas, o uso da internet, smartphones e outros equipamentos que emergiram para facilitar os serviços manuais nas empresas, de como eles passaram a serem adotados pelos gestores com o passar dos anos e como isso afetou a empregabilidade do trabalhador.

Essas inovações proporcionaram mudanças organizacionais profundas, transformando trabalhos e formas 
de gerenciamento, especialmente aqueles ligados aos processos de comunicação e informação, em processos rápidos. Às vezes, velozes demais para determinados trabalhadores acompanharem, fosse por dificuldades em adaptação ou dificuldades cognitivas. A competição gerada entre homem e máquina tem ocasionado retração da QVT por influir diretamente no trabalhador, impactos psicológicos com sintomas somatizados. O medo de ser mais um funcionário obsoleto devido a uma tecnologia fazer seu trabalho melhor poder te substituir, torna a vida do trabalhador complicada quando a empresa não alia essas mudanças à QVT.

Assim, com base nas afirmações bibliográficas encontradas, foi possível sustentar a hipótese proposta: a substituição dos trabalhadores pelas máquinas ocasionam aos funcionários um sentimento emocional de pressão para adequação ao novo funcionamento da corporação (caso contrário eles podem vir a ser os próximos a serem substituídos) levando-os a interferências negativas, como a geração de estresse, aflição, tristeza, ansiedade, baixa produtividade e, por consequência, a diminuição da qualidade de vida dos trabalhadores.

\section{MATERIAL E MÉTODOS}

O estudo utilizou o método qualitativo com delineamento bibliográfico, devido ter sido feito com base em obras já produzidas por outros autores. A pesquisa ainda possuiu o método dialético que teve como finalidade proporcionar informações através da interpretação de acordo com a realidade do fenômeno (GIL, 2008).

Teve-se como amostra 16 artigos científicos que tiveram como critérios de inclusão:

- As publicações deviam apresentar pelo menos uma das palavras-chave: qualidade de vida no trabalho; tecnologia; substituição do trabalhador; informatização do trabalho;

- $\quad$ Elas também deviam estar contidas nas plataformas Scientific Eletronic Library Online (SCIELO) ou Dialnet;

- O período de publicação dos materiais que foram coletados não foi estipulado devido em pesquisas prévias, ter se identificado não haver muitos dados que dizem respeito a investigações com informações precisas de correlação entre as variáveis do estudo.

- Pela mesma razão recém citada, os textos investigados podiam estar em qualquer idioma.

- Os resumos dos artigos precisavam demonstrar relevância para a proposta estabelecida neste estudo, traçando algum viés com saúde mental, discutindo sobre temáticas ligadas às áreas de tecnologia e psicologia ou psiquiatria.
- $\quad$ Excluíram-se as publicações que não apresentavam os indicadores delimitados, não existiam nas plataformas científicas escolhidas ou tinham resumos sem discussão de temas de tecnologia com psicologia ou psiquiatria, isto é, sem apresentar relevância para a área da saúde mental.

Para a organização do estudo, foram criados grupos de análise a partir dos indicadores: qualidade de vida no trabalho; tecnologia; substituição do trabalhador; informatização do trabalho. Para se reunir as informações a partir dos grupos, elaboraram-se fichas de informações, tendo-se coletados os dados compreendidos como mais pertinentes às metas da pesquisa (GIL, 2008).

Em seguida, realizou-se a análise e interpretação qualitativa e dialética, isto é, fez-se a primeira leitura com o foco na exploração do que se tratava determinada obra e, a posteriori, averiguou-se a importância que ela tinha para a pesquisa. Feito isso, partiu-se para a leitura analítica, em que o problema da pesquisa começou a ser respondido. Assim, a interpretação dialética foi realizada pelos pesquisadores visando-se verificar a pertinência dos objetos de estudo e a veracidade da hipótese levantada.

\section{RESULTADOS E DISCUSSÃO}

Desde já, importa-se dizer que a meta empreendida de compreender que interferências negativas a substituição do trabalhador pelas máquinas ocasiona na QVT de uma empresa foi atingida. A hipótese também fora confirmada, ou seja, segundo os dados obtidos, factualmente a substituição do trabalhador pelas máquinas acarreta nos funcionários conflitos emocionais de estresse, aflição, tristeza, ansiedade e baixa produtividade. Tudo isso, decresce a QVT em seu sentido amplo.

\section{Qualidade de vida no trabalho}

A QVT é um termo amplo em sua totalidade. Ao decorrer dos anos, passou por várias modificações em seu conceito, contudo, não deixou de ser o que é em sua essência. Ela já foi muito utilizada nas décadas passadas como forma de produtividade no meio organizacional para que através disso, se pudesse competir no mercado de trabalho (TOLFO; PICCINE, 2001; FERREIRA; ALVES; TOSTES, 2009).

Esse termo surgiu na década de 1950, conforme já citado anteriormente, como um mecanismo para um mercado competitivo e produtivo, que tinha como preocupação a satisfação e o bem-estar do funcionário. Desde então, o termo, tanto na teoria quanto na prática, vem passando por modificações. Na década de 1960, a preocupação com as condições saudáveis do meio organizacional teve avanços, 
agora buscando novas formas de organização do trabalho para que se tivesse um abatimento nos danos causados pelo trabalho e que o funcionário tivesse seu bem-estar alcançado (TOLFO; PICCINE, 2001).

Dentro do Brasil, a preocupação com a QVT, bem como sua prática, surge mais tarde, por volta da década de 1990, com a chegada das tecnologias da informação, da internet. A demanda pela melhoria dos serviços ofertados como método para a competição dentro do mercado de trabalho cresceu, logo se teve a necessidade de se implantar a QVT, tanto nas redes públicas quanto nas redes privadas. As investigações de bem-estar no trabalho também cresceram consideravelmente da década de 1990, sobretudo nas áreas de Administração e Psicologia, que trabalham diretamente com a gestão de pessoas e são os responsáveis por colocar as condições adequadas do meio organizacional em prática (TOLFO; PICCINE, 2001; FERREIRA; ALVES; TOSTES, 2009).

A QVT, em 2000, segundo Tolfo e Piccinini (2001), foi analisada dentro de cinco grandes empresas no Brasil. Descobriu-se que suas maiores qualidades abrangiam a segurança e confiança na gestão, salários e benefícios, o orgulho de trabalhar naquela determinada empresa, clareza nos processos de comunicação e a oportunidade de evolução de carreira. Atrelado a isso, Lacaz (2000), assim como Ferreira, Alves e Toste (2009), frisam sobre uma nova visão organizacional: não basta ter um produto final com qualidade se não trabalhar também a QVT. Essa visão se dá a partir das novas necessidades de mudança de gestão em relação às práticas organizacionais. As mudanças são de grande importância devido às transformações tecnológicas que passam a cercar o mundo ocupacional.

Oliveira e Limongi-França (2005), em suas investigações, dissertam sobre a importância e a preocupação de se implantar a QVT dentro de uma organização. Eles afirmam que muitos dos encarregados sobre o bem-estar no trabalho tendem a não conhecer o que de fato são as boas condições de vida no ambiente laboral. Para eles, adequar o meio organizacional reflete uma ação que se dá através do diagnóstico das condições do local de trabalho para que em seguida sejam feitas as melhorias detectadas como necessárias, sejam de cunho tecnológicos, estruturais ou gerenciais.

A QVT auxilia na produtividade das empresas, no bemestar dos funcionários, na qualidade dos produtos e serviços ofertados. Sabendo-se que muitas pessoas no mercado de trabalho não têm ideia de como lidar com as fortes mudanças ocupacionais, especialmente as tecnológicas, necessita-se que as empresas reflitam sobre um projeto de QVT que os ajude a se adaptar (JACOBSEM, 2000) e que esse processo de adaptação seja o mais indolor possível.

\section{Informatização do trabalho}

Com o surgimento da revolução industrial, pensou-se em novas estratégias no meio de produção. Baseando-se nisso, faz-se necessário falar brevemente do seu contexto histórico para se compreender o tamanho da influência tecnológica no trabalho humano.

O modelo conhecido como Taylorismo, criado por Frederick Taylor no final do século XIX, teve como objetivo principal organizar o sistema de produção nas empresas. Ele sistematizou o meio produtivo, no qual os trabalhadores exerciam suas atividades de forma mais padronizada, justamente para que as indústrias passassem a produzir mais em menos tempo. Junto a isso, surgiu à ideia de Henry Ford, que criou um novo sistema com o mesmo pensamento advindo do Taylorismo, o modelo nomeado de Fordismo. Todavia, ele era mais detalhado e aperfeiçoado, e assim deuse a criação de máquinas que facilitaram a inovação de produtos, pois o empregado não precisaria se locomover para pegar algum instrumento fazendo com que este ficasse sempre na mesma posição ao realizar suas atividades laborais tendo que ser sempre eficiente naquilo que fazia, considerando-se que fazia o mesmo movimento todos os dias (MORAIS NETO, 1986; ABRAHÃO; PINHO, 2002; PAIVA, 2010).

No contexto laboral, falar de informatização no trabalho refere-se ao uso de meios tecnológicos de comunicação ou do uso de equipamentos de grande porte. O uso desses equipamentos enormes foi padronizado no Taylorismo e tiveram uma espécie de upgrade no Fordismo, pois agora toda produção operária era manuseada através de máquinas, tornando-se desnecessário manter-se vários trabalhadores. Criaram-se as linhas de produção em que, muitas vezes, o trabalho do operário resumia-se a apertar algo aqui e prender algo ali, uma peça, por exemplo. Com isso e com a ideia de que o mundo se desenvolvia e se atualizava cada vez mais, houve a necessidade de adaptar-se a essa nova era industrial, em que a cultura organizacional teve, em alguns locais, uma total modificação, levando a necessidade de melhorias internas (MORAIS NETO, 1986; ABRAHÃO; PINHO, 2002).

A década de 1970 é tida como marco para o Brasil, pois passou-se a aderir ao uso das chamadas "novas tecnologias", tendo em vista um único objetivo que era o de gerar melhorias nos negócios. Isso, de fato, enraizou várias atividades feitas à mão como dependentes das tecnologias, sendo quase que impossível o não uso das mesmas (GONÇALVES, 1994).

Santos et al. (2011) conta que ao passar dos anos, com essas inovações e em meio ao contexto social em que elas cresciam, como o surgimento da internet, as empresas melhoraram diversos sistemas funcionais, como a comunicação, algo que mais uma vez, modificou a vida do 
trabalhador: o uso de e-mails eletrônicos para comunicação com os fornecedores que estavam em outras localidades, ligações ou troca de mensagens por smartphones, a venda de produtos via online, de sites ou aplicativos de delivery. Tudo isso gerou acirrada competição na indústria.

Outro recurso tecnológico importante que beneficiou as organizações foi $o$ denominado recursos gerenciais informacionais (GRI), que teve seu surgimento no ano de 1970. Sua finalidade era fazer com que as pessoas ou as máquinas, em determinado ambiente laboral, fossem mais organizados, facilitando-se a solução de diversas problemáticas das organizações, como a fluidez da produção frente à ocupação dos espaços. Em 2007, o GRI passou a ser usado para reter as gamas de informações que a empresa tinha que gerenciar, como a divisão de funções, horários, estoques, gastos, lucros, dependendo do que determinado órgão empresarial oferecia para a sociedade (SANTOS et al., 2011).

A tecnologia tem a função de facilitar a vida da sociedade. Nas empresas, busca-se mais produtividade, crescimento, melhor competitividade (GONÇALVES, 1994; HERÉDIA, 2004; LORENZETTI et al., 2012). Essa relação com o homem e seu ambiente de trabalho merece reflexão e cuidado, especialmente quando se pensa na QVT, dado que uma empresa se desenvolver distante dos avanços tecnológicos parece impensável e receita para o fracasso operacional.

Nesse viés, muitos trabalhadores perdem seus espaços para a tecnologia. É certo que novos inventos tecnológicos vêm para causar mudanças, sejam positivas ou negativas, ocasionando, variadas vezes, a substituição dos trabalhadores por tecnologias. Jacobsem (2000), Abrahão e Pinho (2002) afirmam que a tecnologia possui seus pontos negativos e um deles seria o desemprego, que nos dias de hoje é algo bem presente dentro do mercado de trabalho. Ferreira, Alves e Toste (2009) afirmam que esse aspecto é decorrente das empresas se voltarem à qualidade e produtividade do trabalho para que se tenha um serviço eficaz, procurando-se diminuir o quadro de funcionários e aumentar o investimento em tecnologias, isto é, a tecnologia é capaz de produzir mais e melhor em menos tempo que um ser humano.

Torres e Abrahão (2004) explicam que a substituição dos colaboradores pelas máquinas gera medo nas empresas, na sociedade em geral. Os funcionários têm que buscar estratégias para que possam permanecer na empresa (e serem competitivos no mercado de trabalho) e não serem substituídos por outros profissionais e, consequentemente, pelas tecnologias que podem executar suas funções em um tempo menor. Dessa forma, os funcionários passam por um processo mais delicado, onde os mesmos começam a somatizar os sentimentos resultantes do medo da modificação de seu trabalho pelo advento das tecnologias. Existe receio de que o homem em determinada função, tornese obsoleto.

\section{Aspectos psicológicos}

Com as mudanças no meio laboral, os trabalhos começaram a exigir habilidades de processamento de informações e solução de problemas. Logo, cobra-se muito do cognitivo dos funcionários, nem sempre preparados para isso, se gerando consequências psicológicas. Em variados casos, os funcionários não estão prontos para mudanças tão grandes. Assim, quando um colaborador não é substituído por uma máquina, ele é substituído por outra pessoa com maior capacidade cognitiva para lidar com as mudanças correntes (TORRES; ABRAHÃO, 2004; ANTUNES, 2014).

Antunes (2014) relata que impactos como o medo ou sobrecargas mentais são gerados pela pressão de grandes cobranças para que as tarefas sejam concluídas em um curto espaço de tempo. Tendo em vista que é necessário se adequar ao novo funcionamento da empresa, agora envolvida na informatização cada vez maior, as frustações e os sofrimentos circundante do adoecimento mental podem serem provocadas pela exigência de que os trabalhadores desenvolvam suas atividades do mesmo modo que as máquinas, caso contrário, há demissão (TORRES; ABRAHÃO 2004).

Tais sentimentos supracitados podem acarretar em problemas mais sérios futuramente, pois são dores emocionais causadas por um sofrimento que se não forem verbalizadas, expostas de alguma forma para serem amenizadas e até extinguidas, podem acarretar em patologias (TORRES; ABRAHÃO, 2004). As patologias mais comuns em relação ao fenômeno estudado são a depressão e o estresse ocupacional, que Kamimura e Tavares (2012) trazem em seus estudos como os principais quadros clínicos referentes às doenças mentais ocasionadas pelo trabalho.

Contudo, observa-se que as duas patologias citadas estão interligadas, pois ambas apresentam características parecidas, tais como a somatização dos sintomas gerada pelas emoções advindas da substituição do colaborador em decorrência da tecnologia (JACOBSEM, 2000; TORRES, ABRAHÃO, 2004; MENDES; VIEIRA; MARRONE, 2009; ANTUNES, 2014). Mendes, Vieira e Marrone (2009) afirmam que o sofrimento psíquico desses trabalhadores decorre da dificuldade dos funcionários em se adaptarem ao novo trabalho e ainda não se identificarem com o mesmo. Além disso, há o sentimento de inutilidade por não conseguirem realizar as tarefas propostas somado ao desgaste emocional e físico, bem como ao estresse, próprio das mudanças organizacionais. 
Vale ainda ressaltar que essas consequências interferem na diminuição da QVT dos trabalhadores, afetando, em muitos casos, a vida pessoal deles. Reconhecendo-se a QVT como fator muito importante para os colaboradores de uma empresa desempenharem eficazmente suas tarefas (OLIVEIRA; LIMONGI-FRANÇA, 2005), é válido dizer que em situações como essa, talvez o trabalhador chegue ao ponto de pedir seu desligamento para poder cuidar de sua saúde física e mental. Torres e Abrahão (2004) afirmam que os colaborares alcançam um ponto a qual não conseguem se liberar da sobrecarga psíquica e escolhem, como um meio de defesa ao sofrimento instalado (ou potencial) pelas patologias, deixar suas atividades laborais.

\section{A tecnologia como produto positivo}

Apesar de todas eventuais consequências negativas da tecnologia substituir a mão-de-obra humana, os pontos positivos são também numerosos e são eles que tornam qualquer ideia desse fenômeno parar, uma pura fantasia. Por exemplo, o aumento da produtividade organizacional é uma razão comum e realista das empresas justificarem a inserção maior de tecnologias em seu meio ambiente. Além da produção em menor tempo, otimiza-se a mão-de-obra humana que fizer uso delas (ABRAHÃO; PINHO, 2002; FERREIRA; ALVES; TOSTE, 2009; SANTOS et al., 2011; LORENZETTI et al., 2012). Ou seja, mesmo sendo um fator preocupante para os trabalhadores que não querem perder seus empregos, é algo considerado relevante pelos empresários, afinal podem reduzir os custos com mão-deobra, lucrando, em muitos casos, mais ainda. Essas informações são confirmadas por Abrahão e Pinho (2002) através de seu estudo sobre os desafios da ergonomia. Eles conseguiram identificar que o avanço tecnológico no meio organizacional, com todo seu potencial positivo, tem diminuído a permanência de pessoas dentro das empresas.

Jacobsem (2000) relata, exemplificando, que os funcionários podem trabalhar até mesmo em casa, em home offices, gerando então uma diminuição na jornada de trabalho dos colaboradores e inaugurando novas modalidades de serviços. Herédia (2004) complementa falando que a tecnologia permitiu essa modificação dentro do meio laboral gerando novas funções executivas para manter uma qualidade padrão, como o já discutido GRI (SANTOS et al., 2001). Dessa forma, é possível notar que as empresas só têm a lucrar com os benefícios que as tecnologias the fornecem e a tendência é que elas façam investimentos maiores para a aquisição desse meio mais prático de trabalho, enquanto, em contrapartida, a QVT pode ser afetada ocasionando patologias somatizadas nos colaboradores amedrontados com tantas mudanças, testemunhando colegas serem demitidos e com dificuldades em se adaptar de modo rápido aos avanços tecnológicos implementados. Espera-se que as empresas entendam que aliar resultado e QVT é importante em qualquer mudança organizacional (JACOBSEM, 2000; LACAZ, 2000; OLIVEIRA; LIMONGIFRANÇA, 2005; FERREIRA; ALVES; TOSTE, 2009).

\section{CONSIDERAÇÕES FINAIS}

O estudo gerou reflexões que possibilitaram identificar pontos negativos e positivos acerca dos objetos de estudo. A pesquisa voltou-se a problemática de como a substituição do trabalhador pelas máquinas podem interferir de forma negativa na qualidade de vida dos funcionários de uma empresa. Analisou-se essa mudança, qualitativamente através de revisões bibliográficas, como ela realmente é e suas consequências.

Negativamente, descobriu-se que a substituição dos trabalhadores por máquinas tem verdadeiro potencial de alçar adoecimento mental com sintomas, geralmente, relacionados à baixa estima, às sensações de sobrecargas, somatização dos sentimentos. Não se pode deixar de citar sobre o ponto positivo: benefícios para as empresas que aceleram os processos e atividades internas, e dessa forma fica perceptível que sim, precisa-se repensar as maneiras de se gerir uma organização, e procurar estratégias que beneficiem a empresa tanto em quesito de mão de obra, quanto na produtividade e qualidade dos serviços prestados, pois é certo que toda tecnologia inovadora terá sua influência dentro da organização seja positiva ou negativa.

Recorda-se que os objetos de estudo analisados dentro do proposto aqui ainda são pouco pesquisados no Brasil, assim tem-se a importância de buscar mais sobre o conteúdo, produzir outros conhecimentos, mostrar as consequências geradas, quais métodos usar para evitá-las e ainda estimular o anseio por novos conhecimentos que venham para beneficiar a ciência e ainda proporcionar informações valiosas para o público alvo que são as empresas e seus funcionários.

Diante de tais resultados, foi perceptível que muito ainda precisa ser feito, as empresas precisam buscar meios de organização mais eficazes para que dessa forma, a QVT dos trabalhadores possa se manter intactas e as consequências pela inserção da tecnologia dentro do meio laboral não sejam prejudiciais a ponto de desencadear as patologias como estresse e depressão ocupacional.

\section{REFERÊNCIAS}

ABRAHÃO, J. I.; PINHO, D. L. M. As transformações do trabalho 
e desafios teórico-metodológicos da Ergonomia. Estudos de psicologia. (Natal) [online]. V.7, p.45-52, 2002. Disponível

em: http://www.scielo.br/pdf/epsic/v7nspe/a06v7esp.pdf. Acesso em: 26 abr. 2019.

ABRAHÃO, J. I.; TORRES, C.C. Entre a organização do trabalho e o sofrimento: o papel de mediação da atividade. Revista Produção, v. 14, n.3. p. 067-076, 2004. Disponível em: http://www.scielo.br/pdf/\%0D/prod/v14n3/v14n3a07.pd f. Acesso em: 26. abr. 2019.

ANTUNES. R. Desenhando a nova morfologia do trabalho no Brasil. Estudos avançados. São Paulo, v. 28 n. 81, 2014. Disponível em: http://www.scielo.br/pdf/ea/v28n81/v28n81a04.pdf. Acesso em: 27 abr. 2019.

FERREIRA, M.C.; ALVES, L.; TOSTE, N. Gestão de qualidade de vida no trabalho (QVT) no serviço público federal: O descompasso entre problemas e práticas gerenciais. Psicologia: Teoria e Pesquisa, Brasília, vol. 25 n. 3, p. 319327, Jul-Set $2009 . \quad$ Disponível em: http://www.scielo.br/pdf/ptp/v25n3/a05v25n3.pdf. Acesso em: 25 abr. 2019.

GIL, Antonio Carlos. Métodos e Técnicas de Pesquisa Social. 6. ed. São Paulo: Atlas, 2008.

GONÇALVES, J. E. L. Os impactos das novas tecnologias nas empresas prestadoras de serviços. Revista de administração de empresas [online]. São Paulo, vol. 34, n.1, p.63-81, $1994 . \quad$ Disponível em: http://www.scielo.br/pdf/rae/v34n1/a08v34n1.pdf Acesso em: 25 abr. 2019.

HERÉDIA, V. Novas tecnologias nos processos de trabalho: efeitos da reestruturação produtiva. Revista electrónica de geografía y ciencias sociales. Barcelona, vol. 6, n, 170, s/p, 2004. Disponível em: https://dialnet.unirioja.es/servlet/articulo?codigo=93399 6. Acesso em: 07 jun. 2019.

JACOBSEM, A. L. Implicações do uso da tecnologia de informação como recurso de inovação no ambiente organizacional. Revista de ciências da administração. Florianópolis, v. 2, N. 4, p. 7-19, 2000. Disponível em: https://dialnet.unirioja.es/servlet/articulo?codigo $=51641$ 20. Acesso em: 25 abr. 2019.

KAMIMURA, Q. P.; TAVARES, R. S. C. R. Acidentes do Trabalho Relacionados a Transtornos Psicológicos Ocupacionais. Revista de Gestão em Sistemas de Saúde. São Paulo, v. 1, n. 2, p.140-156, 2012. Disponível em: https://dialnet.unirioja.es/servlet/articulo?codigo $=50374$ 14. Acesso em: 07 jun. 2019.

LACAZ, F.A.C. Qualidade de vida no trabalho e saúde/doença. Ciência \& Saúde Coletiva. Rio de Janeiro, v. 5, n. 1, p. 151161, $2000 . \quad$ Disponível em: http://www.scielo.br/pdf/csc/v5n1/7086.pdf. Acesso em: 25 abr. 2019.

LORENZETTI, Jorge et al. Tecnologia, inovação tecnológica e saúde: uma reflexão necessária. Texto e contexto enfermagem. Florianópolis, v. 21, n. 2, p. 432-439, 2012. Disponível em: http://www.scielo.br/pdf/tce/v21n2/a23v21n2.pdf. Acesso em: 23 mai. 2019.

MENDES, A. M. B.; VIEIRA, A. P.; MARRONE, C. F.Prazer, sofrimento e saúde mental no trabalho de teleatendimento. Revista Eletrônica de Ciência Administrativa (RECADM). Brasília, v. 8, n. 2, p. 151-158, $2009 . \quad$ Disponível em: https://dialnet.unirioja.es/servlet/articulo?codigo $=40591$ 99. Acesso em: 07 jun. 2019.

MORAES NETO, B. R. Maquinaria, taylorismo e fordismo: a reinvenção da manufatura. Revista de administração de empresas. São Paulo, v. 26, n. 4, p. 31-34, 1986. Disponível em: http://www.scielo.br/pdf/rae/v26n4/v26n4a03.pdf. Acesso em: 23 Mai. 2019.

OLIVEIRA, P. M.; LIMONGI-FRANCA, A. C. Avaliação da gestão de programas de qualidade de vida no trabalho. Revista de administração de empresas [online]. São Paulo, v. 4, n. 1, $2005 . \quad$ Disponível em: http://www.scielo.br/pdf/raeel/v4n1/v4n1a05.pdf. Acesso em: 26 abr. 2019.

PAIVA, T. A. Taylorismo e Fordismo na indústria paulista: o empresariado e os projetos de organização racional do trabalho, 1920 - 1940. Revista de administração contemporânea. Curitiba, v. 14, n. 2, p. 392-393, 2010 Disponível em: http://www.scielo.br/pdf/rac/v14n2/v14n2a16.pdf. Acesso em: 23 mai. 2019.

SANTOS et al. Estruturação da área de informação em saúde a partir da gerência de recursos informacionais: análise de experiência. Revista Panamericana de Salud Pública. São Paulo, v. 29, n. 6, p.409-415, 2011.Disponível em: https://www.scielosp.org/pdf/rpsp/2011.v29n6/409415/pt. Acesso em: 28 abr. 2019.

TOLFO, R.S.; PICCINE, V.C. As melhores empresas para trabalhar no Brasil e a qualidade de vida no trabalho: Disjunções entre a teoria e a prática. Revista de Administração Contemporânea, São Paulo, v. 5, n. 1, p. 165-193, Jan./Abr. 2001. Disponível em: http://www.scielo.br/pdf/rac/v5n1/v5n1a10. Acesso em: 25 abr. 2019..

Submissão: $12 / 02 / 2020$

Aprovado para publicação: 18/04/2020 